\title{
DGPS AND MAGNETOTELLURIC CONSTRAINTS ON THE CONTEMPORARY TECTONICS OF THE SANTORINI VOLCANIC COMPLEX, GREECE
}

\author{
Papageorgiou E. ${ }^{1}$, Tzanis A. ${ }^{1}$, Sotiropoulos $\mathbf{P}^{1,2}$ and Lagios E. ${ }^{1}$ \\ ${ }^{1}$ University of Athens, Department of Geophysics and Geothermy, Zografou 15784, Greece, \\ epapageo@uoa.gr \\ ${ }^{2}$ TERRAMENTOR E.E.I.G., Sarantaporou Str. \& Str. Tompra 10, Ag. Paraskevi, 153 42, Greece, \\ terramen@otenet.gr
}

\begin{abstract}
The study of vertical and horizontal crustal movements at the Santorini Volcanic Complex (SVC), as deduced by Differential GPS measurements revealed that an intricate pattern of five distinct domains with different horizontal kinematics: The West SVC (Akrotiri peninsula and Therassia) with very significant $N N W$-ward motion, North Thera with rather significant NW-ward motion, East Thera (Monolithos), with significant SE-ward motion, South Thera with significant NW-ward motion and, finally, central Thera with small westward motion. An apparently dextral, NNW-SSE oblique-to-strike-slip fault emerges as a prominent tectonic structure, separating the West SVC from the rest of the complex; this is the "Santorini Fault Zone". Additional insight is afforded by the results of MT and GDS surveys: a significant NNW-SSE conductive zone was detected, which is collocated with the purported NNW-SSE fault zone indicated by DGPS analysis and may be explained as an epiphenomenal conductivity anomaly. The observed deformation pattern enables the drafting of a qualitative model of contemporary tectonics, which is also presented and discussed. The model is plausible but certainly incomplete and pending verification with numerical modelling and additional observations.
\end{abstract}

Key words: Santorini, Differential GPS, Magnetotellurics, tectonic deformation.

\section{Introduction}

We report the results of a joint interpretation of Differential GPS (DGPS) and MagnetoTelluric (MT) data, in an attempt to identify and study the contemporary crustal deformation in the area of the Santorini Volcanic Complex (SVC). This multi-centre back-arc volcanic field is located at a break point of the central Hellenic Volcanic Arc (HVA) and comprises a very active locale featuring a large flooded caldera, formed at approx. 1650 B.C.

Ground deformation in back-arc volcanoes is associated with tectonic and volcanic processes, namely regional and local scale faulting and/or magma motion. In the reposed state, ground deformation is primarily a result of tectonic activity. During a paroxysmal period, magma motion assumes the primary role and deformation may serve as a precursor to eruptive activity; in this case the ground surface is expected to dilate (bulge) or contract in response to inflationary or deflationary changes in the magma chamber and the activity associated with the emplacement of dikes at the 
upper parts of the volcanic edifice, which is anyway facilitated by the preferential paths created by tectonic activity. The study of ground deformation may assist in understanding the interplay between tectonic and volcanic processes and, in turn provide additional insights into volcanic hazards.

Ground deformation studies at the SVC have been reported by Stiros and Chasapis (2003) and Stiros et al., (2003). Their observational evidence was based on a radial EDM geodetic network comprising 10 stations on the perimeter of the caldera (and in close proximity to the rim), and one central station on Nea Kammeni islet; the particular choice of network layout has not been adequately explained. Based on intermittent observations of radial baseline length changes during the interval 1994-2001, they claim to have detected a phase of temporary dilation with particular expression at North Thera, where a maximum of $9.5 \mathrm{~cm}$ was observed. The dilation was attributed magmatic processes (inflation of a small magma chamber under some part of the volcano). These results will be re-evaluated herein, in the light or our new DGPS observations. Ground deformation observations continue at present (e.g. Farmer et al., 2007), but they are based on a single DPGS baseline of only two continuously recording stations, established in 2006. In consequence, hitherto results are neither adequate, nor representative of ground deformation.

DGPS has proven to be an important tool for intermediate and long-term monitoring of active volcanoes, as it provides high resolution 3-D information about the deformation field (e.g. Dvorak and Dzurisin, 1997; Fernandez et al., 1999 and many others). At the SVC, DGPS measurements conducted during the period 1994-2005 have detected non-trivial amounts of ground displacement, in both the horizontal and vertical axes (e.g. Papageorgiou et al., 2007). This enabled the identification of several domains with different kinematic characteristics, which will be further discussed and interpreted herein.

We will argue that the observed differential deformation is primarily the result of differential motion across faulting structures located at the boundaries between the deforming domains. However, the very low seismicity rates, combined with the discontinuous operation of local seismological networks for short exposure periods, does not allow these faulting zones to be directly identified by conventional seismotectonic analysis. Only recently have permanent seismographic networks been installed in the area (see http://ismosav.santorini.net) and the emerging earthquake data set is still incomplete.

As it turns out, there is an opportunity to clarify the situation using magnetotelluric (MT) data, independently collected at Santorini as part of another research project (Lagios et al., 1996). This may provide indirect (geoelectric) albeit well constrained images of the suspected faulting structures and thus assist in their identification.

The reason why observations of the geoelectric structure can image tectonic processes can be traced to the epiphenomenal development of electrical conductivity anomalies in response to faulting. Within the schizosphere, (brittle upper crust), faulting generates permeable rock, either directly within the fault zone, (fault gouge, breccias and mylonite), or around it as a result of repeated cycles of loading / unloading and elasto-plastic deformation. The presence of water in the immediate neighbourhood of the fault zone is very important factor for tectonic processes, as it influences creep and/or stability. Around the fault, tectonically induced permeability resulting from micro- and mesoscale fracturing, and crack interconnection is generally aligned with the fault. Healing processes are expected to close the cracks and reduce conductivity, unless they are kept open by continuous accumulation of deformation, either seismic or aseismic. Moreover, the more extensive and pervasive the microfracturing, (more heavily deformed the material), the more conductive the rock may be. Geothermal (hydrothermal) areas and volcanic domains in the upper crust are particular environments deserving special attention. The electrical conductivity of near surface rocks arises from the fluid 


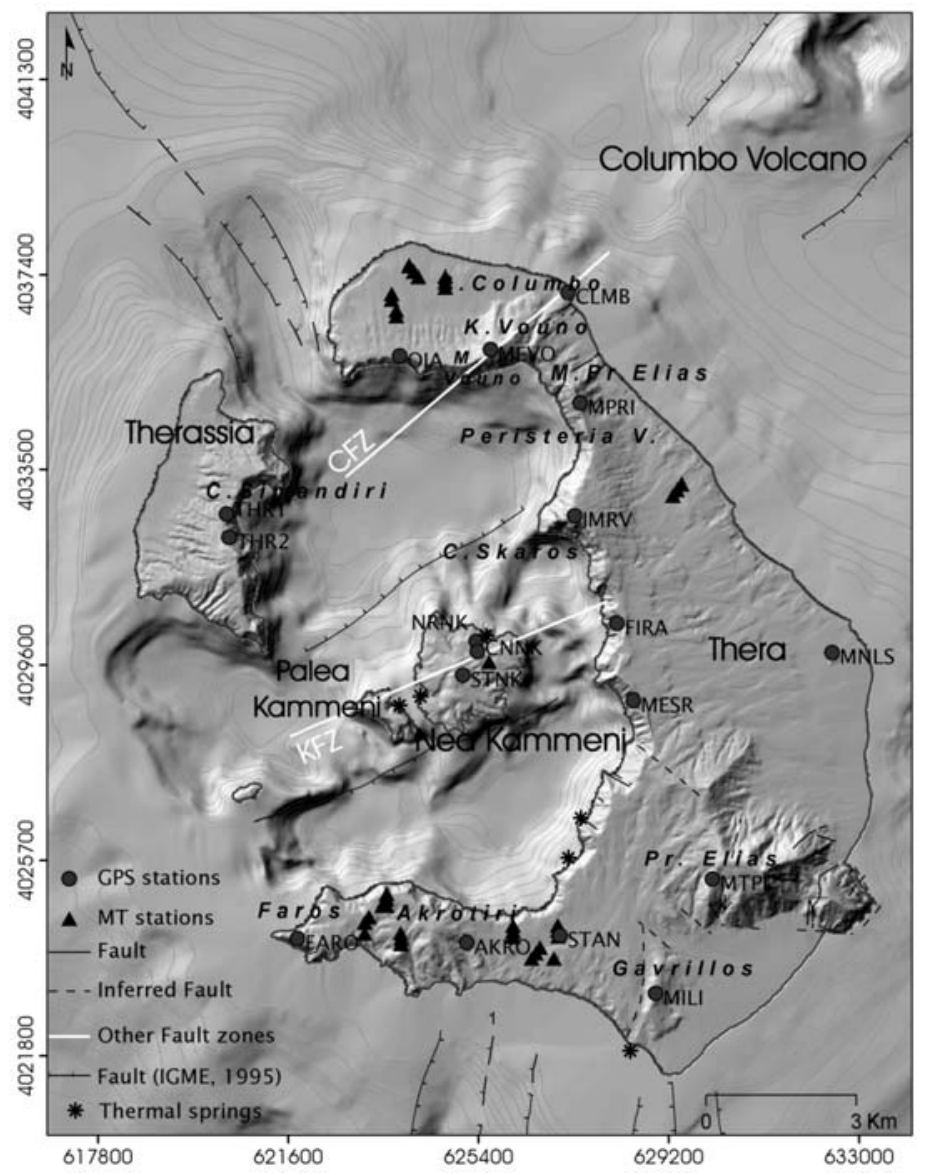

Fig. 1: Simplified map showing the main structural features along the Santorini volcanic complex. Circles represent GPS sites, triangles the MT stations, asterisks the location of thermal springs. CFZ: Columbos Fault KFZ: Kammeni Fault.

content of interconnected pore space (liquid fraction) and depends on the salinity of the pore fluids, the temperature and the presence or absence of clay minerals. Clay minerals may increase the salinity of pore fluids, (hence electrical conductivity), by several orders of magnitude. The liquid fraction will certainly increase in the neighbourhood of fluid circulation conduits, as also will the fraction of clay minerals due to hydrothermal alteration. In convective geothermal systems, especially those controlled by concurrent tectonic activity, circulation conduits are usually identified with the dominant active fault systems through which fluids are transported from the deep feeder reservoirs or heat sources. This is also true for all geological situations associated with active circulation of subterranean waters.

\section{Tectonics and volcanism}

The SVC (Fig. 1) is part of the HVA developing ad retro of the Hellenic Arc and Trench, in an area characterized by extensional regional tectonics which had a profound effect in its evolution. The volcanic activity is dated to at least 1.6 Ma BP (Ferrara et al., 1980). The last significant eruption 
has taken place in 1950 and at present, volcanic activity is limited to thermal venting at the locations shown in Figure 1.

The northern part of the island complex lies in a graben, probably the continuation of the Anhydros Basin (Perissoratis 1995). Most of the effusive activity since $530 \mathrm{ka}$, which includes the Peristeria Volcano, the Simandiri shield, the Skaros shield, the Therassia dome complex, and the Kammeni Volcano has been associated with this feature. The contemporary volcanism is manifested by two major volcanic centres, the Nea Kammeni Volcano rising at the centre of the caldera and the submarine Columbos Volcano, located $7 \mathrm{~km}$ NE of Cape Coloumbo (Fig. 1). Their evolution has been affected by two distinct NE-SW tectonic lineaments, the Kammeni and Columbos Fault Zones respectively (Druitt et al., 1989, 1999). These mark the alignment of several eruptive vents and have been interpreted to comprise major normal faults (Pe-Piper \& Piper, 2005). Six Plinian eruptions were aligned along Kammeni Fault Zone. Independent volcanic centres at North Thera, as is the Megalo Vouno cinder cone, the Kokkino Vouno cinder cone and the Cape Columbos tuff ring define the Columbos Fault (for details see Fouqué, 1879 and Reck, 1936). In addition, several dykes located at northern Thera, have a NE-SW orientation, as for instance the one between Mikros Profitis Ilias and Megalo Vouno (Heiken \& McCoy 1984; Mountrakis et al., 1998). The southern half of the island is situated at the northern flank of a NE-SW-trending basement horst, the Santorini-Amorgos Ridge (Perissoratis 1995). Part of the basement rocks is outcropping at SE Thera (Mt Profitis Elias and Mt Gavrillos).

Direct evidence of faulting at different orientations is found in both geological maps of the SVC (Pichler et al., 1980; Druitt et al., 1999) and is reproduced in Figure 1. The faults comprise short strands with a general NW-SE orientation, observable mainly at South Thera and on the walls of the caldera. A significant NNW-SSE depression between North Thera and Therassia, bears evidence of normal faulting (IGME, 1995; Perissoratis, 1995); the same feature has been interpreted to be, either an extended NW-SE dyke (Pichler and Kussmaul, 1980) or the result of rotational slumping (Heiken and McCoy, 1984). Earthquake activity at and around the SVC is manifested with small magnitude earthquakes and low seismicity rates. The majority of earthquake foci are concentrated around the Columbos volcano, with fairly low activity observed at the rest of the complex (Delibasis et al., 1989; Drakopoulos et al., 1996; Bohnhoff et al., 2006; ISMOSAV, http://ismosav.santorini.net). At present, it is not clear which part(s) of this activity is of tectonic or of volcanic origin.

\section{GPS observations and results}

A GPS network comprising 18 re-occupiable stations has been established on the SVC (Fig. 1) and was intermittently measured during numerous campaigns during the interval $1994-2005$. The interested reader may find details about the field measurement and data reduction procedures in $\mathrm{Pa}-$ pageorgiou et al. (2007). Herein, the results are presented in terms of average deformation rates (velocities) with accuracies of a few $\mathrm{mm} / \mathrm{yr}$. Differences in the vertical motion between stations are better observed and interpreted when referred to a global coordinate system, in this case the ITRF2000 (e.g. Altamini et al, 2002). Conversely, differences in the horizontal motion are overly smoothed when referred to a global reference frame, while they are better resolved and interpreted in local frames. Accordingly, Figure 2 shows the vertical displacement rates (velocities) in the ITRF2000 reference frame, while Figure 3 illustrates the horizontal displacement rates relative to site MTPI. The selection of the reference station was based on geological criteria, as it is located on the alpine basement, NE of Thera, on apparently stable Upper Triassic limestones.

The vertical velocity results show subsidence at the centre of the caldera, at Nea Kammeni islet, (STNK, $-6 \pm 2 \mathrm{~mm} / \mathrm{yr}$; CNNK, $-2.1 \pm 0.3 \mathrm{~mm} / \mathrm{yr}$ ) as well as at Southern Thera with maximum rates at 


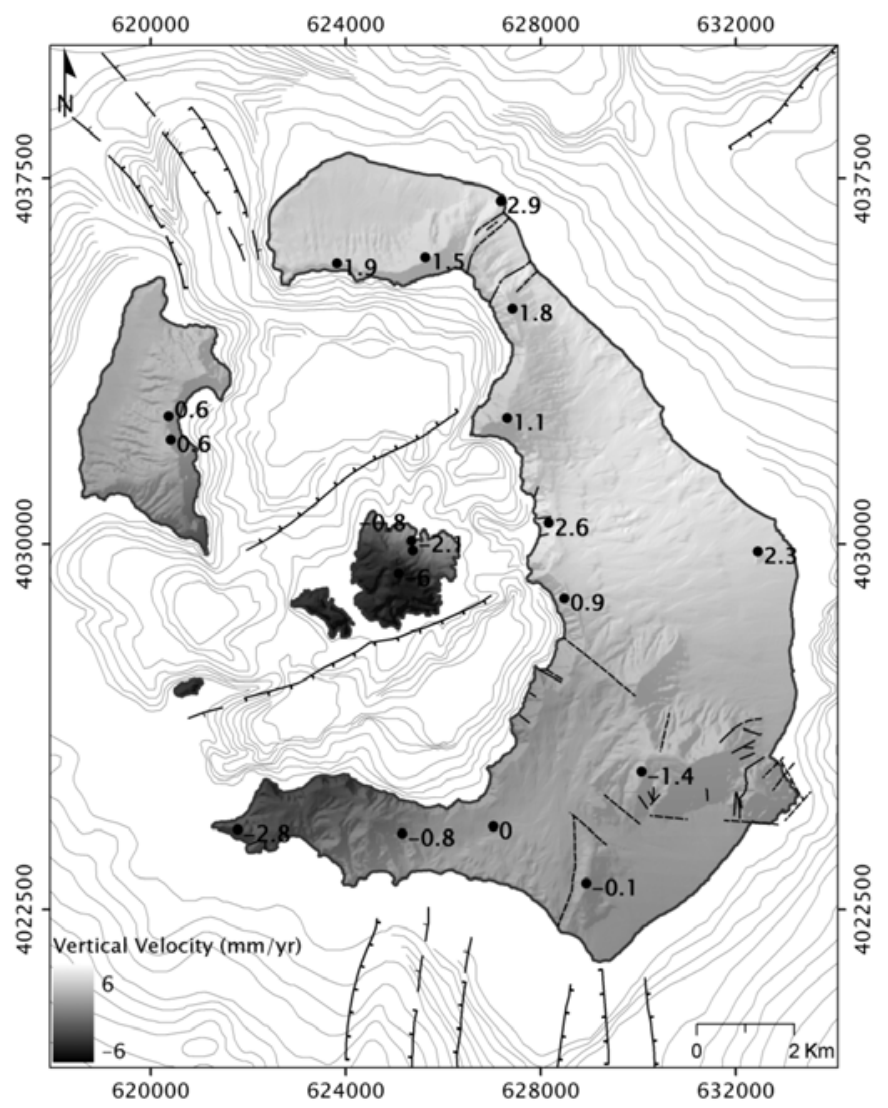

Fig. 2: Vertical deformation rates for the period 1994-2005 in the ITRF2000 reference frame. Dark shades indicate subsidence, bright shades uplift.

the terminus of the Akrotiri peninsula (FARO, $-2.8 \pm 0.5 \mathrm{~mm} / \mathrm{yr}$ ). Notably, the northernmost station at Nea Kammeni (NRNK) shows a much smaller rate of subsidence $(-0.8 \pm 0.1 \mathrm{~mm} / \mathrm{yr})$, possibly related to some interface between the northern-central and southern parts of the islet; this could be the Kammeni Fault. Relative stability is observed at Therassia Island (THR1, 0.6 $\pm 0.4 \mathrm{~mm} / \mathrm{yr}$ ), while the rest of the network shows uplift with maximum rate at CLMB $(2.9 \pm 0.1 \mathrm{~mm} / \mathrm{yr})$.

In terms of vertical kinematics and at first sight, the SVC would appear to comprise two major domains, NE Thera and Therassia experiencing uplift and SW Thera and the Kammeni islets experiencing subsidence. However, the geometry of the uplift/subsidence distribution is peculiar (arcuate) and the rates of uplift and subsidence are definitely not uniform across each domain - this indicates that the causative mechanisms are much more intricate (and certainly not consistent with explanations involving simple fault geometries).

The horizontal velocity field indicates a very complex kinematic pattern, with significant rates for the majority of the stations (see Fig. 3). Very significant NNW - NW-ward motion is observed at the western SVC and specifically at Therassia and Akrotiri Peninsula, with rates in excess of $3 \mathrm{~mm} / \mathrm{yr}$ and an average $\mathrm{N} 340^{\circ}$ orientation. North Thera is associated with slightly smaller rates (up to $2 \mathrm{~mm} / \mathrm{yr}$ ) and $\mathrm{N} 290^{\circ}-\mathrm{N} 310^{\circ}$ orientations. The difference in the displacement rate observed between stations OIA, MEVO and CLMB on one hand, and MPRI on the other $(\sim 0.7 \mathrm{~mm} / \mathrm{yr})$, may indicate differen- 


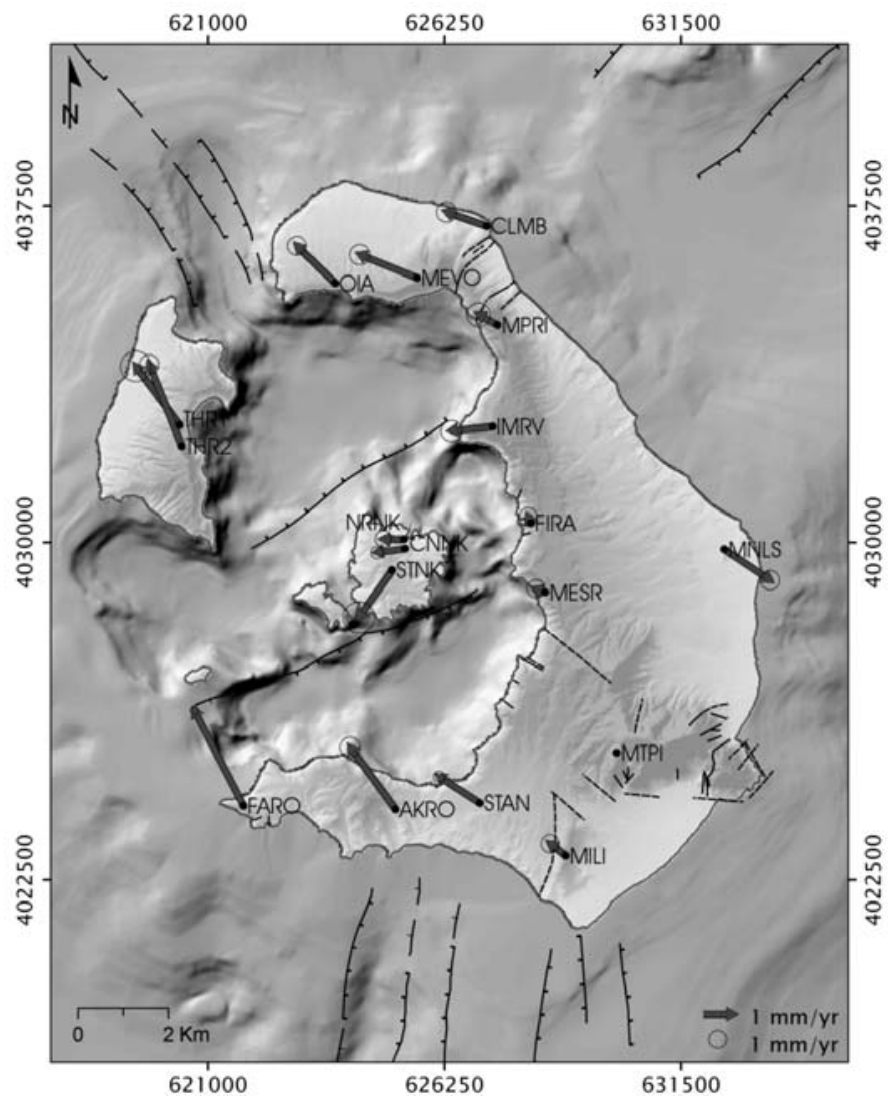

Fig. 3: Horizontal deformation rates relative to MTPI for the period 1994-2005.

tial motion across a normal fault dipping to the SE, which may well be the Columbos Fault. Analogous observations can be made elsewhere: The two southernmost stations, STAN and MILI, exhibit uniform NW direction of motion $\left(\mathrm{N} 300^{\circ}\right)$ but with quite different rates, possibly indicating the existence of an active discontinuity between them, in a sense analogous to the purported differential displacement across the Columbos Fault. Finally, the station at Monolithos (MNLS) is a sui generis beast, exhibiting SE-ward motion at $\sim \mathrm{N} 120^{\circ}$, almost exactly antiparallel to the motion observed at STAN, MILI and North Thera. Most of the stations located at central Thera, near the rim of the caldera, between Emerovigli (IMRV) and Messaria (MESR), as well as the stations on Nea Kammeni, exhibit altogether different kinematics with low horizontal deformation rates in a west to WSW-ENE direction $\left(\mathrm{N} 255^{\circ}-\mathrm{N} 270^{\circ}\right)$. There are three exceptions: at Fira and Messaria, where the rate is insignificant and cannot be appraised, and at south Nea Kammeni (STNK), where it is significant and SSW oriented. These are additional sui generis results, further perplexing the interpretation.

It appears that the SVC comprises five distinct domains with different horizontal kinematics relative to station MTPI: The West SVC (Akrotiri peninsula and Therassia) with significant NNW-ward motion, North Thera: with rather significant NW-ward motion, East Thera (Monolithos), with significant SE-ward motion, antiparallel to that of North and South Thera, South Thera with significant NW-ward displacement, sub-parallel to that of North Thera and, finally, Central Thera with westward motion and small displacements. This is a very complex pattern and certainly difficult to interpret. 
Nevertheless, it allows two definitive observations to be made:

1. The overall kinematics indicates that in the interval $1994-2005$, the causative effect is a complex tectonic regime rather than some form of a magmatic process (emplacement). This is consistent with the current reposed state of the SVC, which showed no signs of activity before, during and after the GPS experiment. It is inconsistent with the interpretation of Stiros and Chasapis (2003) and Stiros et al., (2003), reported in Section 1, according to which there has been small scale dilation of a part of the volcano, probably due to minor inflation of a magma chamber. The main line of evidence against this hypothesis comes from the arrangement of the horizontal component of the deformation field, which is certainly not compatible with centrally driven inflation: this would have a distinctive pattern, quite different from the observed. The contribution of magmatic processes cannot be ruled out, but they are not likely to have occurred at an appreciable scale, due to the absence of any companion phenomena (e.g. elevated heat flow, increased hydrothermal activity etc.). The contribution of other volcanic processes cannot be resolved at present; if any, they should be more important in the immediate vicinity of the Kammeni Volcano. It appears that the interpretation of Stiros and co-workers is a consequence of inadvertent bias stemming from the geometry of the network: it was designed to detect radial deformation patterns and so it did, because the relative motion between the different blocks of the SVC is distributed in such a way, that all the radial baselines were bound to change lengths with the observed sign!

2. The differential horizontal motion between the West SVC (Therassia and Akrotiri peninsula) on one hand and the rest of the SVC on the other is very significant. The horizontal kinematics of the former are almost uniform, while in the latter they are intricate and indicative of complex tectonics as discussed above. It is therefore safe to conclude that a major tectonic discontinuity of NNW-SSE orientation $\left(\sim \mathrm{N} 340^{\circ}\right)$ exists between the two domains, as shown in Figure 6, this purported fault will henceforth be referred to as the Santorini Fault Zone (SFZ).

\section{Magnetotelluric Data Analysis and Results}

The MagnetoTelluric (MT) survey was conducted during the summer of 1993 (Lagios et al., 1996), providing a total of 34 soundings (Fig. 1). Fairly standard observation procedures were followed, leading to the acquisition of five cartesian components of the natural EM field over the nominal frequency bandwidth 130-0.01 Hz. The data was infested by significant anthropogenic ambient noise, so that advanced processing methods were required (Egbert and Booker, 1986; Tzanis and Beamish, 1988) in order to obtain Earth response functions (MT Tensor Impedances and Magnetic Transfer Functions) with acceptable levels of uncertainty.

The spatial analysis of the magnetotelluric Earth response endeavours to extract information about the configuration of the induced natural EM fields, which, in turn, depend on the geometry and configuration of lateral inhomogeneities in the geoelectric structure. The spatial analysis of the impedance tensor used herein is the Canonical Decomposition of Yee and Paulson (1986). It is not possible to show in this thrifty presentation, but it approaches the geoelectric structure as the equivalent of a birefringent material at low frequencies and large scales. In this context, there is a fast - resistive direction of propagation in which the apparent impedance (resistivity) is maximal, and a slow - conductive - direction in which the apparent impedance is minimal. Given that the local direction of the electric field indicates the local direction of current flow and assuming (quasi) two-dimensional local and regional structures, the spatial analysis of the impedance tensor boils down to the following simple rules (see also Swift,1971): 


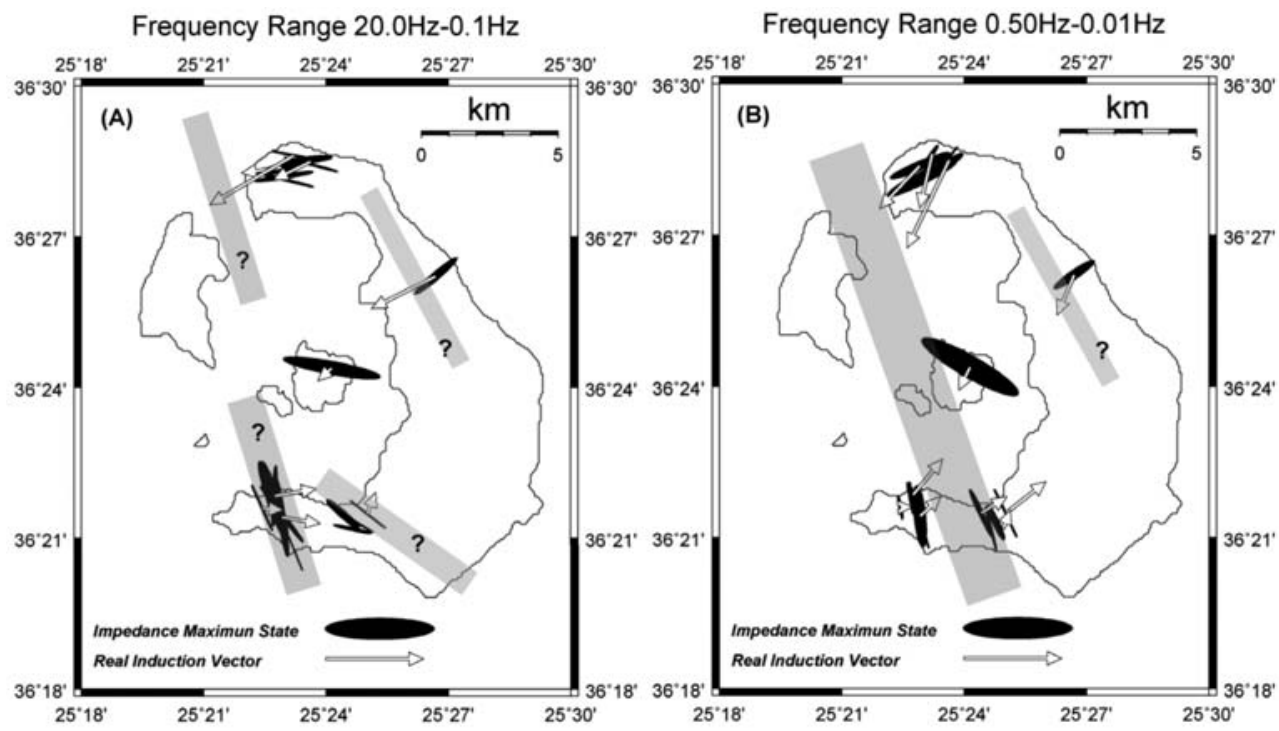

Fig. 4: The maximum characteristic states of the electric field (maximum impedance) and the real induction vectors, averaged (A) over the band $20-1 \mathrm{~Hz}$ and (B) over the band $0.5-0.01 \mathrm{~Hz}$. The thick gray lines represent the approximate location of elongate conductors.

- On the conductive side of a lateral interface, the maximum electric field (maximum state) will be parallel to the strike of the interface and will correspond to the Transverse Electric (TE) mode of EM field propagation.

- On the resistive side of an interface, the maximum electric field will be normal to the strike and will correspond to the Transverse Magnetic (TM) mode of EM field propagation.

The spatial analysis of the MTF is based on the Induction Vector (IV) representation. The IV comprises a magnitude and an azimuth that defines the normal to the local strike of the anomalous concentration of current which produces the anomalous magnetic field. Two such vectors are defined for vertical fields responding in-phase (real) and out-phase (imaginary) with the horizontal component with which the vertical field exhibits maximum correlation; for 2-D or quasi-2D inhomogeneities they should be parallel or anti-parallel and perpendicular to the strike of the inhomogeneity (e.g. Rokityansky, 1982). Herein we only make use of the real IV for simplicity and brevity. The vector is drawn in the Parkinson convention, so that it will point towards current concentrations, i.e. towards resistivity interfaces.

In a final step and following the above discussion, the properties of the MTTI and the MTF can be combined, leading to the following simple rules for the spatial analysis of 2D structures:

- On the resistive side of a (quasi)2-D interface, the maximum electric field and the real IV are approx. parallel, the IV pointing towards the interface.

- On the conductive side of a (quasi)2-D interface the maximum electric field and the real IV are approx. orthogonal, the IV pointing towards the interface.

The results of the spatial analysis are presented in Figure 4. Figure 4a shows the polarization ellipse of the maximum electric field and the real IV, averaged over the frequency interval $20-1 \mathrm{~Hz}$; these frequencies correspond to a relatively shallow part of the geoelectric structure.(see also Fig. 5). The 
overall configuration of the electric field and current flow indicates that the shallower part of the geoelectric structure has dominant 2-D attributes with approx. $\mathrm{N} 330^{\circ}-340^{\circ}$ oriented structural trends. At the northern part of Thera, the data indicate TM mode induction over the resistive part of a quasi2D structure, the interface apparently being located at the area of the channel between Thera and Therassia. At Akrotiri peninsula the data show two distinct domains: The cluster of measurements at the western part of the peninsula, near cape Faros, indicates TE mode induction over the conductive side of a structure; the cluster at the eastern part near Akrotiri town, indicates TE mode as well, albeit driven by a structure and interface with an apparently different configuration of $\mathrm{N} 300^{\circ}$ $310^{\circ}$. The geographical distribution of the measurements allows placement of two conductors, one oriented $\mathrm{N} 330^{\circ}-340^{\circ}$ at the western cluster of measurements and one oriented $\mathrm{N} 310^{\circ}-320^{\circ}$, just east of Akrotiri town. Finally, the sole sounding at Nea Kammeni cannot be interpreted with confidence, as it has attributes of near-filed three-dimensionality.

Figure $4 \mathrm{~b}$ shows the polarization ellipse of the maximum electric field and the real IV averaged over the frequency interval $0.5-0.01 \mathrm{~Hz}$, which corresponds to relatively deep parts of the geoelectric structure (of the order of $2-5 \mathrm{~km}$, see also Fig. 5). The overall configuration of the electric field and current flow indicates that the deeper structure also has prevailing 2-D attributes, without being sensu stricto 2-D, and appears to be simpler and smoother than the shallower structure indicated by Figure 4a. Only one large scale structural trend with $\mathrm{N} 320^{\circ}-330^{\circ}$ strike is detected and comprises a relatively broad elongate conductor extending between, and inclusive of, the Akrotiri peninsula and the Kammeni islets. This zone is delineated by the TM mode at the N-NW part of Thera and the TE mode at the southern part and Kammeni islets.

Two-dimensional inversion was carried out along a transect of approximately W-E orientation, between Faros and Akrotiri town; this is the only place where MT measurements are available in numbers and spacing sufficient to warrant the exercise. Inversion was performed with the algorithm of Rodi and Mackie (2001), assuming that the maximum electric field represents induction in the TE mode, as concluded by the spatial analysis above. In all cases, a discretized homogenous half-space was used as a starting model; the discretization scheme is apparent in Figure 5. Topography was also taken into consideration. Several inversions with different regularization factors were carried out before a final model was declared. The results are shown in Figure 5, where the approximate location of the interfaces (faults) detected by the spatial analysis are also included in the presentation (dashed lines). The most prominent geoelectric features observable in Figure 5 are two sub-vertical conductive zones, one near Faros at the west and one east of Akrotiri town, which are apparently associated with the conductivity interfaces and are interpreted to be sub-vertical faults or fracture zones of high secondary permeability. These are separated by a relatively resistive zone. Finally, it is apparent that an extensive lateral conductive formation exists at and just below sea level, which is thought to represent sea-water intrusion.

\section{Interpretation and Conclusions}

We have presented an analysis and joint interpretation of data collected with two methods of geophysical inquiry which, at first sight, might appear to form an unlikely twosome: Differential GPS and Magnetotellurics. Each method has its own means of detecting crustal faulting: GPS relies on kinematics and MT relies on the detection of elongate epiphenomenal conductivity anomalies.

The joint analysis has detected a major structural feature comprising an elongate zone of hefty changes in kinematic characteristics, apparently collocated with an elongate conductivity anomaly. This straddles the entire SVC approximately along the line defined by Akrotiri, the strait between 


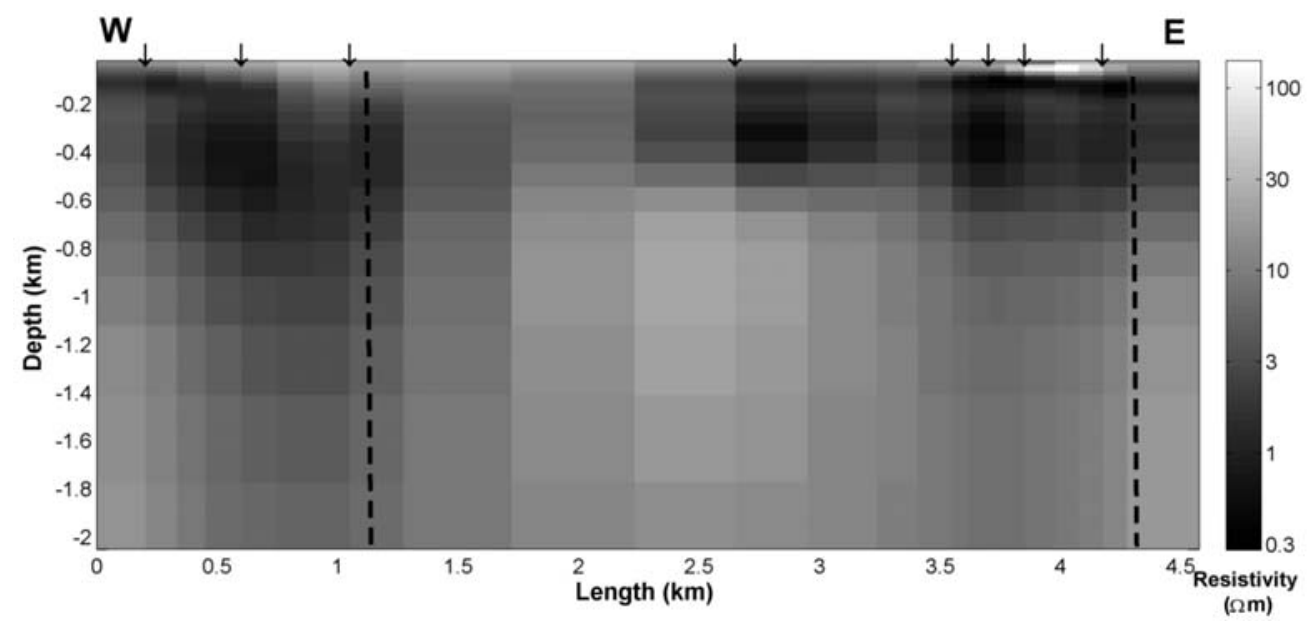

Fig. 5: Geoelectric image of the upper two kilometres of the crust, along the Akrotiri peninsula, obtained with two-dimensional inversion. Depths refer to mean sea level.

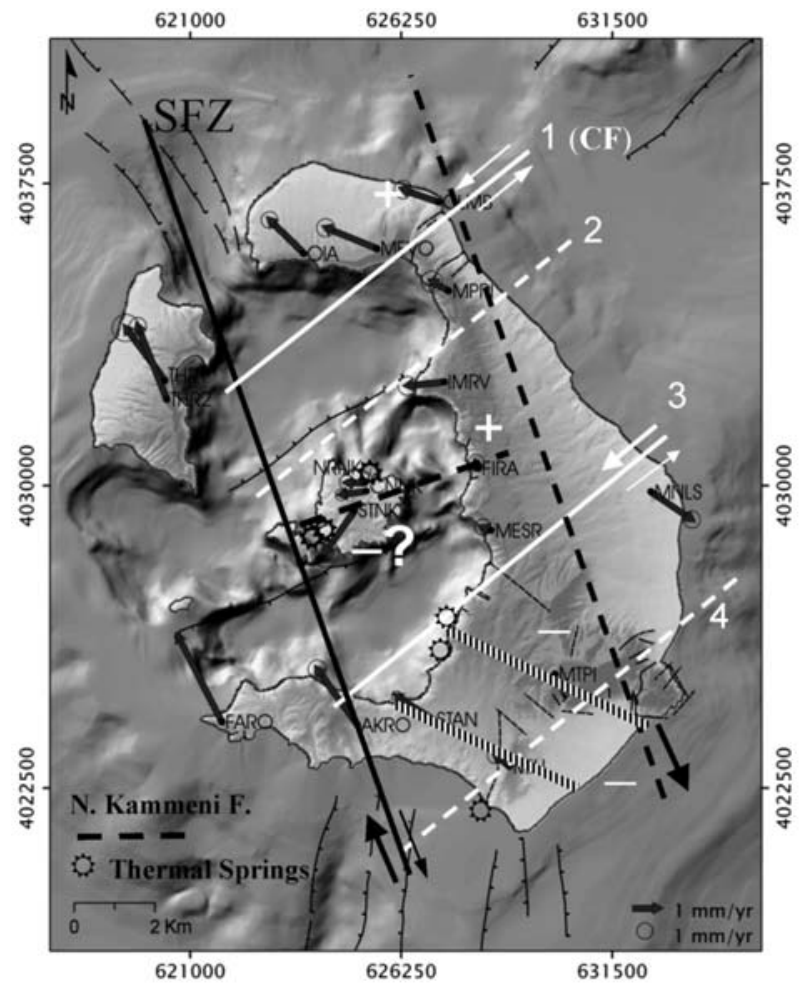

Fig. 6: Tentative interpretation of the DGPS and MT/GDS observations at the Santorini Volcanic Complex.

Palaea and Nea Kammeni islets and the strait between Thera and Therassia (see Fig. 6). This is interpreted to comprise an expression of a major NNW-SSE $\left(\sim \mathrm{N} 340^{\circ}\right)$ trending tectonic discontinuity, which we tentatively dub the Santorini FZ. Given that at the west SVC the net horizontal 
displacement is significantly higher than the net vertical displacement, the SFZ appears to be dextral and oblique-normal to strike-slip. A second expression of the SFZ may separate East Thera from the rest of the SVC; this is tentatively depicted with a dashed line collocated with the conductor detected by the sole MT/GDS sounding measured at the area. The SFZ has not been detected before, although it appears to dominate the tectonics of the SVC.

This major zone aside, the SVC exhibits very complex kinematics, which at its present reposed state is more comfortably understood in terms of tectonics rather than volcanic processes (see discussion in Section 3). A tentative and purely qualitative interpretation is shown in Figure 6.

The numbered white lines represent a system of oblique-normal faults with a rather significant sinistral horizontal slip component. The exact orientation of these faults is not known (and cannot be known without detailed kinematic modelling) but they are tentatively assumed to comprise extensions/ expressions of the Anhydros Basin fault system (ABFS) extending between Amorgos Island and the SVC. Their net horizontal displacement is assumed to be considerably smaller than that of the SFZ, so that their combined action would result in the net NW-ward $\left(\mathrm{N} 300^{\circ}-\mathrm{N} 320^{\circ}\right)$ horizontal motion at North and South Thera and the SE-ward $\left(\mathrm{N} 120^{\circ}\right)$ motion at East Thera. Line 1 coincides with the Columbos Fault; extension across this discontinuity may account for the differential motion between stations MFVO and MPRI. Line 2 has been placed as to separate the NW-ward moving North Thera from the westward moving Central Thira; it is also approximately collocated with a fault of similar orientation, mapped on the caldera walls (Pichler et al., 1980) and the bathymetry (IGME, 1995). Line 3 is marks the boundary between Central and South Thera. Finally, Line 4 is tentatively placed to account for the differential displacement between STAN and MILI, in a fashion analogous to the effect observed at North Thera, between MFVO and MPRI. The SFZ is apparently acting as a barrier to the horizontal motion of the ABFS.

The vertically hatched line corresponds to a zone of local extension formed due to the simultaneous action of SFZ and ABFS, which is also hosting an epiphenomenal conductor detected by the MT/GDS data. Together with a second such zone placed just south of MTPI and in association with the thermal springs at the southern perimeter of the caldera, it may form a local graben-like structure with orientation $\sim \mathrm{N} 300^{\circ}$, whose $\mathrm{NW}$-ward extension is consistent with a depression observed just south of Therassia. This structure may account for the differences in the subsidence rates observed at South Thera. Nevertheless, it is an apparently shallow and local feature, as it vanishes/ merges with the SFZ at greater depths. Similar zones/ structures may exist elsewhere in the SVC but cannot be detected with the existing MT station layout.

The above interpretation is far from being complete or comprehensive. Some major questions still pending are as follows:

- It cannot fully explain the kinematics of Central Thera and the local peculiarities at FIRA and STNK stations. The westward motion there might be due to faster motion of the block defined by Lines 2 and 3 relative to the SFZ; this block includes the Kammeni volcano and the associated special thermal regime, which complicates matters and renders inadequate any attempt to explain the deformation in terms of a simple shearing model. In addition, the role of the Kammeni fault, if any, is still not clear and has not been taken into consideration. In conclusion, the true origin of the observed kinematics at Central Thera is unknown.

- It cannot explain the entire spectrum of observed vertical motions, particularly at Nea Kammeni, presumably for similar reasons.

- It cannot fully explain both the vertical and the SE-ward orientation of the horizontal motion of Monolithos (MNLS) due to the dearth of data in that area and the resulting difficulty to rec- 
ognize local peculiarities.

Thus, with the exception of the well defined SFZ, the proposed model of contemporary deformation at the Santorini Volcanic Complex, albeit plausible, should rather be viewed as a basis for discourse and a starting point for future investigations. In fact, its verification relies on future investigations, a cardinal part of which should be quantitative (numerical) modelling in order to reproduce the observed kinematics, as well as additional geological and geophysical observations with an improved GPS network.

\section{Acknowledgments}

The collection and analysis of MT data was financed by the European Union, through contract EV5V-CT93-0285. The collection and analysis of GPS data was financed by (i) The European Union (75\%), (ii) The General Secretariat for Research \& Technology (25\%), and (iii) Terramentor E.E.I.G. The valuable involvement of Dr. Vasileios Sakkas in the GPS field campaigns is dully acknowledged. The knowledgeable advice of Dr. Haralambos Kranis is also cordially appreciated.

\section{References}

Altamini, Z., Sillard, P. and Boucher, C., 2002. ITRF2000: A new release of the International Terrestrial Reference Frame for Earth Science applications. J. Geophys. Res., 107(B10), 2214, doi:10.1029/2001JB000561.

Bohnhoff, M., Rische, M., Meier, Th., Becker, D., Stavrakakis, G. and Harjes, H-P., 2006. Microseismic activity in the Hellenic Volcanic Arc, Greece, with emphasis on the seismotectonic setting of the Santorini-Amorgos zone. Tectonophysics, 423, 17-33.

Delibasis, N., Chailas, S. and Lagios, E., 1989. Surveillance of Thera Volcano-Microseismicity Monitoring. Proc. 3rd Intern. Congress "Thera and the Aegean World", 2, Sept. 3-9, Santorini, Greece, 109-206.

Drakopoulos, J., Makropoulos, C., Stavrakakis, G., Panagiotopoulos, D., Papanastasiou, D., Hatzidimitriou, P., Papazachos, C., Vargemezis, G. and Savvaidis, A., 1996. Seismic monitoring of Santorini Volcano: Seismological network and processing of the seismological data. Santorini Volc. Lab., II, 15.

Druitt, T.H., Mellors, R.A., Pyle, D.M. and Sparks, R.S.J., 1989. Explosive volcanism on Santorini, Greece. Geological Magazine, 126, p. 95-126.

Druitt, T.H., Edwards, L., Mellors, R.M., Pyle, D.M., Sparks, R.S.J., Lanphere, M., Davies, M. and Barreiro, B., 1999. Geological Map of the Santorini Islands, 1:20000. Geological Society of London, Memoir, 19, 178p.

Dvorak, J.J. and Dzurisin, D., 1997. Volcano geodesy; the search for magma reservoirs and the formation of eruptive event. Rev. Geophys., 35, 343-384.

Egbert, G.D. and Booker, J.R., 1986. Robust estimation of geomagnetic transfer functions. Geophys. J. R. astr. Soc., 87, 173-194.

Farmer, G.F, Newman, A.V., Psimoulis, P., Stiros, S., 2007. Geodetic Characterization of Santorini Caldera from Continuous GPS Measurements. EOS.

Fernández, J., Carrasco, J.M., Rundle, J.B. and Arána, V., 1999. Geodetic methods for detecting volcanic unrest: A theoretical approach. Bull. Volcanol., 60, 534-544.

Ferrara, G., Fytikas, M., Guiliano, O. and Marinelli, G., 1980. Age of the formation of the Aegean active volcanic arc. In: Doumas C. (ed). Thera and the Aegean World II, 37-41.

Fouqué, F., 1879. Santorin et ses eruptions. Masson et Cie., Paris, 440p.

Heiken, G. and McCoy, F., 1984. Caldera development during the Minoan eruption, Thera, Cyclades, 
Greece. J. Geophys. Res., 89, 8441-8462.

I.G.M.E., 1995. Surficial sediment map of the bottom of the Aegean Sea, Scale 1:200,000: Santorini sheet, IGME, Athens, Greece.

Jackson, J.A., 1994. Active tectonics of the Aegean region. Annual Reviews of Earth and Planetary Sciences, 22, 239-271.

Lagios, E., Galanopoulos, D., Sotiropoulos, P. and Vougioukalakis, G., 1996. Audio-Magnetotelluric study of Thera Volcano. Santorini Volc. Lab., II, 10.

Mountrakis, D., Pavlides, S., Chatzipetros, A., Meletidis, S., Tranos, M., Vougioukalakis, G. and Kilias, A., 1998. Active deformation in Santorini. In: Casale R., Fytikas M., Sigvaldarsson G. \& Vougioukalakis G. (eds). The European laboratory volcanoes. European Commission, EUR 18161, 13-22.

Papageorgiou, E., Lagios, E., Vassilopoulou, S. and Sakkas, V., 2007. Vertical \& Horizontal Ground Deformation of Santorini Island deduced by DGPS measurements. Proceedings of the 11th International Conference Geol. Soc. Greece, Athens, Greece. Bull. Geol. Soc. Greece, 40, 1219-1225.

Pe-Piper, G. and Piper, D.J.W., 2005. The South Aegean active volcanic arc: relationships between magmatism and tectonics. Develop. in Volc., 7, 113-133.

Perissoratis, C., 1995. The Santorini volcanic complex and its relation to the stratigraphy and structure of the Aegean Arc, Greece. Marine Geology, 128, 37-58.

Pichler, H. and Kussmaul, S., 1980. Comments on the geological map of the Santorini Islands. In: Doumas, C. (ed.). Thera and the Aegean World II. The Thera Foundation, London, 413-427.

Pichler, H., Guenther, D. and Kussmaul, S., 1980. The Geological Map of Greece. Thira Island, Inst. Geol Min. Exploration, Athens 1980.

Reck, H., 1936. Santorini. -Der Werdergang eines Inselvulcans und sein Ausbruch 1925-1928. Dietrich Reimer, Berlin, 3 vols. MANCA.

Rodi, W. and Mackie, R.L., 2001. Nonlinear conjugate gradients algorithm for 2-D magnetotelluric inversion, Geophysics, 66, 174-187.

Rokityansky,I.I., 1982. Geoelectromagnetic investigations of the Earth's Crust and Mantle. Springer Verlag.

Stiros, S. and Chasapis, A., 2003. Geodetic monitoring of the Santorini (Thera) volcano. Survey Review, $37,287,84-88$.

Stiros, S., Chasapis, A. and Kontogianni, V., 2003. Geodetic evidence for slow inflation of the Santorini Caldera. Proceedings, 11th FIG Symposium on Deformation Measurements, Santorini, Greece.

Tzanis, A. and Beamish, D., 1989. A high resolution spectral study of audiomagnetotelluric data and noise interactions. Geophys. J., 97, 557-572.

Yee, E. and Paulson, K.V., 1987. The Canonical decomposition and its relationship to other forms of magnetotelluric impedance tensor analysis. J. Geophys., 61, 173-189. 